\title{
LETTERS
}

\section{Canada needs equitable, earlier access to palliative care}

We commend Downar and colleagues for their research on early experiences of medical assistance in dying (MAiD) in Ontario. ${ }^{1}$ However, we have to question their interpretation that people are not requesting MAiD owing to lack of access to palliative care, because of the inadequacies of their data.

As clinicians, we find that palliative care is often consulted at the time of a MAiD request. The study does not show how the authors determined that a patient received palliative care, nor how long before the MAiD request that palliative care was initiated. The authors use an Ontario study ${ }^{2}$ to compare data on palliative care access in MAiD recipients and interpreted its data, which showed access by $74.4 \%$ of MAiD recipients versus the other study's $47 \%$, as evidence that MAiD requests did not result from lack of access to palliative care. A 2017 Ontario study ${ }^{3}$ found that $38.8 \%$ of patients had their first palliative care access in the last month before death, and $12.0 \%$ in the second month before death. This study concluded there is a large variation in the intensity and timing of care, with many receiving little care, and a substantial proportion of care initiated and delivered close to death. This conclusion is supported by a 2018 Canadian Institute for Health Information study ${ }^{4}$ that showed most palliative care services were received only in the last month of life, and that more than $80 \%$ receiving palliative care in hospital were admitted through emergency, demonstrating that palliative care is not accessed early or systematically in Canada. The same study examined 349 records of MAiD in hospital between June 2016 and March 2016 and found $70 \%$ were identified as palliative on their last hospital admission, where they received MAiD.

Previous research ${ }^{5,6}$ has illustrated that individuals with months of high levels of disease burden (physical, emotional and spiritual or existential distress) and the convergence of certain psychosocial factors leads to depression and hopelessness, and ultimately to a desire for hastened death. Providing palliative care to those who have already been suffering for months and thus end up distressed and suffering enough to request hastened death is most often providing palliative care too late. This is not even to mention the substantial minority of $22.8 \%$ of MAiD recipients in the study by Downar and colleagues ${ }^{1}$ who apparently had no palliative care involvement whatsoever at any time before medically assisted death.

We find that the suggested conclusion, from less-than-transparent data, is unsupported and more of a political statement than research.

There remains a well-known ${ }^{4,7-9}$ need for earlier, equitable access to palliative care for all Canadians with a serious illness.

\section{Romayne Gallagher MD}

Palliative care physician (retired), Providence Health Care, Vancouver, BC

\section{Michael J. Passmore MD}

Psychiatrist, Providence Health Care, Vancouver, BC

Cite as: CMAJ 2020 May19;192:E559. doi: 10.1503/cmaj.74961

\section{References}

1. Downar J, Fowler RA, Halko R, et al. Early experience with medical assistance in dying in Ontario, Canada: a cohort study. CMAJ 2020;192:E173-81.

2. Brown CR, Hsu AT, Kendall C, et al. How are physicians delivering palliative care? A populationbased retrospective cohort study describing the mix of generalist and specialist palliative care models in the last year of life. Palliat Med 2018;32:1334-43.

3. Tanuseputro P, Budhwani S, Bai YQ, et al. Palliative care delivery across health sectors: a population-level observational study. Palliat Med 2017;31:247-57.

4. Access to palliative care in Canada. Ottawa: Canadian Institute for Health Information; 2018. Available: www.cihi.ca/sites/default/files/document/ access-palliative-care-2018-en-web.pdf (accessed 2010 Feb. 19).

5. Rodin G, Lo C, Mikulincer M, et al. Pathways to distress: The multiple determinants of depression, hopelessness, and the desire for hastened death in metastatic cancer patients. Soc Sci Med 2009;68:562-9.

6. Lo C, Zimmermann C, Rydall A, et al. Longitudinal study of depressive symptoms in patients with metastatic gastrointestinal and lung cancer. $J$ Clin Oncol 2010;28:3084-9.

7. Tung J, Chadder J, Dudgeon D, et al. Palliative care for cancer patients near end of life in acute-care hospitals across Canada: a look at the inpatient palliative care code. Curr Oncol 2019;26:43-7.

8. Costante A, Lawand C, Cheng C. Access to palliative care in Canada. Healthc Q 2019;21:10-2.

9. Xiong B, Freeman S, Banner D, et al. Hospice use and one-year survivorship of residents in longterm care facilities in Canada: a cohort study. BMC Palliat Care 2019;18:100.

Competing interests: None declared. 